\title{
Interleukin-18-induced inflammatory responses in synoviocytes and chondrocytes from osteoarthritic patients
}

\author{
ZHAOZONG FU, PENG LIU, DEHONG YANG, FENGLONG WANG, \\ LIANG YUAN, ZHEN LIN and JIANMING JIANG
}

\author{
Department of Spine Surgery, Nanfang Hospital, Southern Medical University, Guangzhou 510515, P.R. China
}

Received April 23, 2012; Accepted June 28, 2012

DOI: 10.3892/ijmm.2012.1073

\begin{abstract}
The major pathological changes of osteoarthritis (OA) include cartilage degeneration and synovial inflammation. Previous studies confirmed that interleukin-1 (IL-1) stimulates the secretion of multiple inflammatory factors in synoviocytes and chondrocytes. IL-18 is a member of the IL-1 superfamily. In this study, the pro-inflammatory effects of IL-18 on synoviocytes and chondrocytes in patients with OA were investigated. Knee synovial membrane and cartilage samples were obtained from OA patients, then primary cells were cultured. Synoviocytes and primary chondrocytes at different generations (primary, secondary and tertiary), were stimulated with IL-18, then inflammatory marker levels, including tumor necrosis factor- $\alpha(\mathrm{TNF}-\alpha)$, prostaglandin $\mathrm{E}_{2}$ $\left(\mathrm{PGE}_{2}\right)$ and cyclooxygenase-2 (COX-2), were measured using reverse transcription polymerase chain reaction (RT-PCR) and enzyme-linked immunosorbent assay. IL-1 receptor antagonist (IL-1Ra) was applied to interfere with the IL-18 stimulation of chondrocytes, and then the COX-2 expression in chondrocytes and the $\mathrm{PGE}_{2}$ levels in the medium were measured. The expression of IL-18 receptor $\alpha$ (IL-18R $\alpha$ ) and IL-18 receptor $\beta$ (IL-18R $\beta$ ) in synoviocytes and chondrocytes was assessed, using RT-PCR. Our results showed that IL-18 stimulated the COX-2 and TNF- $\alpha$ expressions in primary synoviocytes, while increasing $\mathrm{PGE}_{2}$ and TNF- $\alpha$ levels in the supernatant $(\mathrm{P}<0.05)$ of the culture medium in primary synoviocytes. IL-18 also induced high $\mathrm{PGE}_{2}$ level production in second-generation synoviocytes $(\mathrm{P}<0.05)$. Moreover, IL-18 upregulated COX-2 and TNF- $\alpha$ mRNA in chondrocytes, while promoting $\mathrm{PGE}_{2}$ and TNF- $\alpha(\mathrm{P}<0.05)$ secretions in a dose-dependent manner. The induced effects were not attenuated by the addition of
\end{abstract}

Correspondence to: Professor Jianming Jiang, Department of Spine Surgery, Nanfang Hospital, Southern Medical University, 1838 North Guangzhou Avenue, Guangzhou 510515, P.R. China

E-mail: jjm19991999@sohu.com

Key words: osteoarthritis, synoviocytes, chrondriocytes, inflammatory response, interleukin-18
IL-1Ra $(\mathrm{P}<0.05)$. IL-18R $\alpha$ was expressed in the chondrocytes and synoviocytes of $4 / 8$ patients, while IL-18R $\beta$ was expressed in the chondrocytes of $4 / 8$ patients and in the synoviocytes of $2 / 8$ patients. We conclude that IL-18 induces inflammatory responses in synoviocytes and chondrocytes and that this effect was correlated with, although not entirely dependent on, IL-1 $\beta$.

\section{Introduction}

The major pathological changes in osteoarthritis (OA) include synovial proliferation and cartilage degeneration that involve several inflammatory factors. Cartilage damage is one of the primary pathological characteristics of OA. Cartilage fragments enter the synovial fluid, irritating the synovial membrane and leading to synovitis. The inflamed synovial membrane subsequently releases inflammatory mediators, which further degenerate cartilage, thereby forming a vicious circle. Thus, synovitis is the main cause for knee cartilage damage and chronic degeneration in OA (1). Elevated expression of interleukin-1 (IL-1), a crucial pro-inflammatory cytokine, is often observed in the synovial membrane in patients with OA. The imbalance between the IL-1 receptor (IL-1R) and the IL-1 receptor antagonist (IL-1Ra) is correlated with the severity of OA (2). IL-1 $\beta$ has the potential to stimulate chondrocytes to produce several inflammatory factors, including nitric oxide (NO), inducible nitric oxide synthase (iNOS), prostaglandin- $\mathrm{E}_{2}\left(\mathrm{PGE}_{2}\right)$ or matrix metalloproteases (MMPs) (3), leading to the inflammatory response of chondrocytes as well as the degradation of the cartilage matrix (4-6).

IL-18 has a structure similar to that of IL-1 and is therefore acknowledged as a member of the IL-1 super family (7). Initially, T-cell-produced IL-18 was found to be able to induce interferon- $\gamma($ IFN- $\gamma)$ production, and was subsequently named IFN- $\gamma$-inducing factor. IL-18 is derived from an inactive precursor. The mature and functional $18 \mathrm{kDa}$ IL-18 protein molecule is generated through enzymatic cleavage $(7,8)$. IL-18 has multiple biological activities, while being crucial for the pathogenesis of rheumatoid arthritis, especially synovitis. IL-18 can be detected in the synovial fluid in the knees in patients with rheumatic arthritis (RA). IL-18 receptor (IL-18R) is also expressed in the synovial membrane in RA-affected joints (9-11). A continuous low-level IL-18 expression, tumor 
necrosis factor- $\alpha$ (TNF- $\alpha$ ), granulocyte macrophage-colony stimulating factor (GM-CSF) and IL-1 $\beta$ were reported in fibroblast-like synoviocytes (FLS) in the synovial membrane of RA and OA patients as well as in the synovial fluid of spondyloarthropathy (SpA) patients (12). A study analyzing the impact of high-level IL-18 on synoviocytes and peripheral blood monocytes in RA patients demonstrated that IL-18 had a more prominent pro-inflammatory effect on peripheral blood monocytes (12).

The response of synoviocytes in OA patients to IL-18 remains unclear. In OA, destruction of articular cartilage mainly results from the imbalance between the synthesis and the degradation of cartilage. IL-1 and TNF- $\alpha$ are essential in stimulating chondrocyte catabolism (13). IL-1 triggers $\mathrm{PGE}_{2}$ production as well as the expression of COX-2 and iNOS (14). However, IL-18 also induces the expression of genes, such as iNOS, COX-2 and IL-6, leading to the degeneration and inflammation of chondrocytes (14). IL-18 inhibited the in vitro proteoglycan production in the patella of young rats in the presence of IL-1 (15). Nevertheless, the effect of IL-18 on OA chondrocytes and the role of IL-1 $\beta$ and IL-18 in these processes remains unclear.

In this study, we investigated the effect of IL-18 on the synoviocytes and chondrocytes of patients with OA. We also detected the expression of IL-18 receptors in the two types of cells, and examined the relationship between IL-18 and IL-1 in the pro-inflammatory process.

\section{Materials and methods}

Cell culture. Synoviocytes and chondrocytes were collected from 8 patients with OA (5 females and 3 males; average age, 62.3 years). The patients provided informed consent prior to sample collection. This study was monitored and approved by the Medical Ethics Committee of the Nanfang Hospital.

Synoviocytes were cultured in vitro in accordance with the methods described by Zimmermann et al (16). The synovial tissue was washed twice using sterile phosphate-buffered saline (PBS). The sample was cut into sections in PBS and digested with $0.1 \%$ trypsin at $37^{\circ} \mathrm{C}$ for $30 \mathrm{~min}$. The tissue was then placed in Dulbecco's modified Eagle's medium (DMEM) containing $0.1 \%$ type I collagenase (Sigma, St. Louis, MO, USA) and $10 \%$ fetal bovine serum (FBS) for $2 \mathrm{~h}$. After filtration and centrifugation, the cells were collected and cultured in medium with penicillin and streptomycin, for 7 days at $37^{\circ} \mathrm{C}$ in a $5 \%$ carbon dioxide environment and transferred to a 6-well plate. Synoviocytes were classified as described in the study by Franke et al (17). Identical numbers of primary, secondary and tertiary cells were starved in DMEM for $24 \mathrm{~h}$. The cells were then transferred and cultured in fresh medium containing IL-18 $(10 \mathrm{mM} / \mathrm{ml})$ for an additional $24 \mathrm{~h}$. The cultured cells and supernatants were harvested for additional analysis.

Articular cartilage collected from the femur condyle and tibial plateau in the surgeries of total knee joint arthroplasty was cut into 2-3 $\mathrm{mm}^{3}$-sized pieces and then washed with DMEM three times. The sample was digested in $10 \%$ trypsin at $37^{\circ} \mathrm{C}$ for $15 \mathrm{~min}$. The digested tissue was then collected and mixed with $0.2 \%$ type II collagenase (Gibco, Carlsbad, CA, USA) and $0.1 \%$ hyaluronidase (Sigma) at $37^{\circ} \mathrm{C}$ in a shaker for $6 \mathrm{~h}$. Cells were washed with DMEM to remove proteases and filtered through a sterile cell strainer. Primary cells were suspended and cultured in DMEM supplemented with $10 \%$ FBS. The expression of type II collagen was then analyzed. Selected primary cells were seeded onto 6-well plates and cultured in medium with different concentrations of IL-18 ( 0 , 50,100 and $200 \mathrm{ng} / \mathrm{ml}$ ) for $48 \mathrm{~h}$.

Immunohistochemistry. Sterilized coverslips $(8 \mathrm{x} 8 \mathrm{~mm})$ were placed onto 6-well plates. Cells were seeded and cultured for $24 \mathrm{~h}$, allowing cells to attach to coverslips. After incubation, coverslips were washed three times with PBS, for $3 \mathrm{~min} / \mathrm{wash}$, and treated with $3 \%$ hydrogen peroxide and normal serum to block intrinsic peroxidases and proteins possibly generating non-specific cross reactions. After the removal of residual serum, coverslips were incubated with rabbit polyclonal antibodies against type I and type II collagen (Boster, China) in a wet box at $4^{\circ} \mathrm{C}$ overnight. The following day, polyclonal goat anti-rabbit secondary antibodies (Boster) were applied to the coverslips at $37^{\circ} \mathrm{C}$ for $30 \mathrm{~min}$. After washing, the coverslips were incubated with horseradish peroxidase substrates and diaminobenzidine (DAB) and then examined under an inverted microscope.

Cytokine detection. Supernatants from cultured cells were collected and centrifuged in $1.5 \mathrm{ml}$ microcentrifuge tubes at $3,000 \mathrm{x} \mathrm{g}$ for $10 \mathrm{~min}$ and then stored in a $-80^{\circ} \mathrm{C}$ freezer. The concentration of cytokines in the samples was assayed simultaneously. Standard curves were plotted following the manufacturer's instructions ( $\mathrm{PGE}_{2}$; Uscn Life Science, Inc., Wuhan, China) (TNF- $\alpha$; Cusabio Biotech Co., Ltd., Wuhan, China) and the $\mathrm{PGE}_{2}$ and TNF- $\alpha$ concentrations in the samples were then determined using enzyme-linked immunosorbent assay (ELISA).

RT-PCR analysis. Total-mRNA was extracted from synoviocytes and chondrocytes using TRIzol (Invitrogen, Carlsbad, CA, USA). The concentration mRNA concentration was determined using a NanoDrop Spectrophotometer (Wilmington, NC, USA). Reverse transcription was performed using a reverse transcription kit (Toyobo, Japan) The reaction conditions were as follows: $30^{\circ} \mathrm{C}$ for $10 \mathrm{~min}, 42^{\circ} \mathrm{C}$ for $20 \mathrm{~min}$ and $95^{\circ} \mathrm{C}$ for $5 \mathrm{~min}$. The $\Delta \Delta \mathrm{Ct}$ method was applied for the quantitative analysis (18). Primer sequences used in this study were: aggrecan, forward: 5'-TGA GTC CTC AAG CCT CCT GT-3' and reverse: 5'-GTC CCT CTG TCT CCT TGC AG-3'; TNF- $\alpha$, forward: 5'-TCT CTT CAA GGG ACA AGG CTG-3' and reverse: 5'-ATA GCA AAT CGG CTG ACG GT-3'; COX-2, forward: 5'-TGA ACC CAC TCC AAA CAC A-3' and reverse: 5'-CAG CAA ACC GTA GAT GCT CA-3'. PCR products were analyzed using agarose gel electrophoresis. The levels of IL-18R $\alpha$ and IL-18R $\beta$ expressions were determined as described in the study by Moller et al (19).

Statistical analysis. Statistical analysis was performed using the SPSS 13.0 software. Cytokine concentrations in the supernatant from cultured cells were shown as the mean \pm SE. $\mathrm{P}<0.05$ was considered to indicate a statistically significant difference. Two independent-sample t-tests were conducted to analyze the effects of IL-18 on synoviocytes. The effects of 

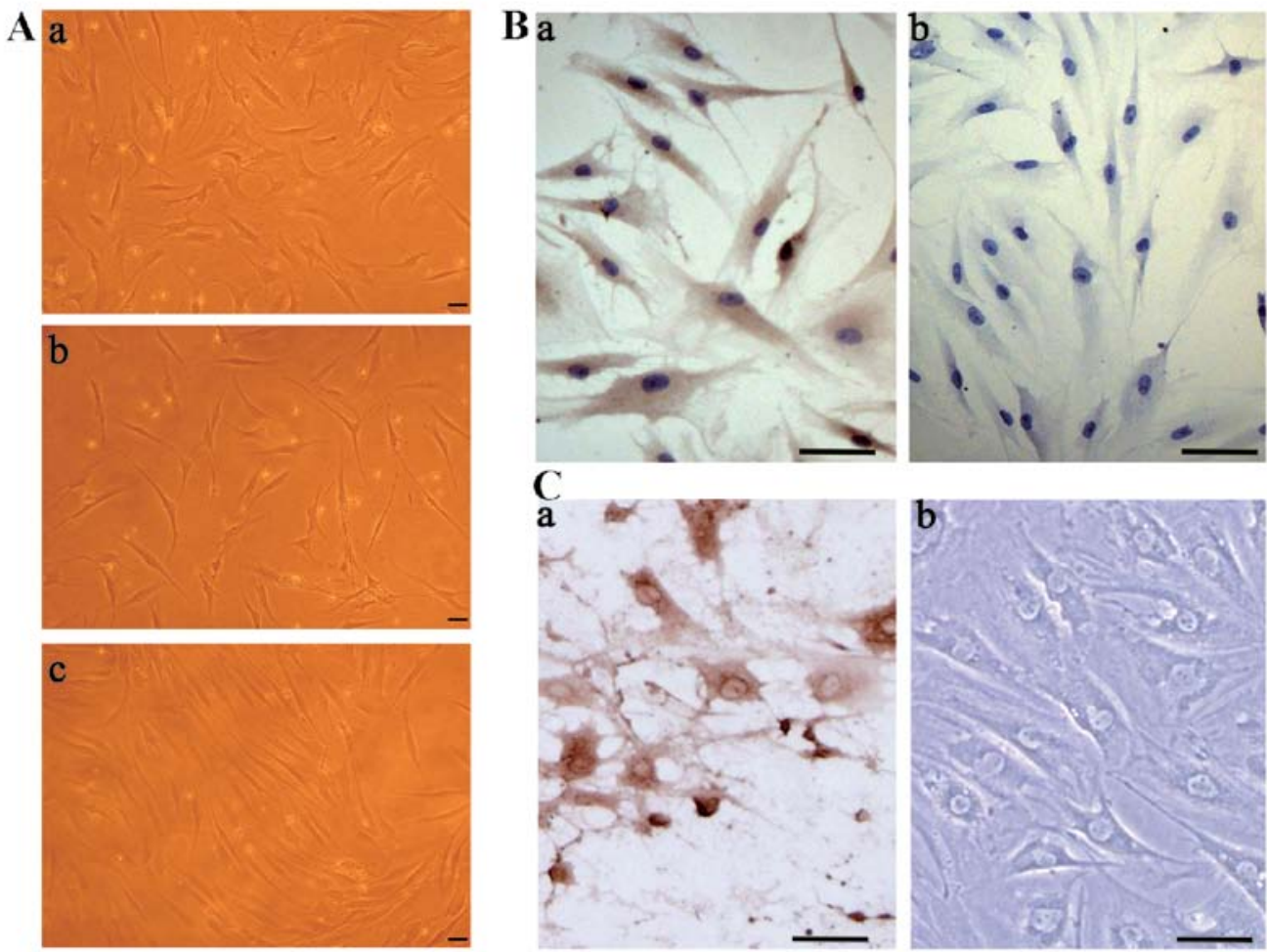

Figure 1. Morphological observation and characterization of synoviocytes and chondrocytes. (Aa-c) Most of the cells in the 1st-3rd generation synoviocytes derived from OA patients were spindle-shaped. Synoviocytes were stained with (Ba) type I collagen antibody, or with (Bb) rabbit serum as a negative control. Chondrocytes were stained with (Ca) type II collagen antibody, or with (Cb) rabbit serum as a negative control. Bars, $100 \mu \mathrm{m}$.
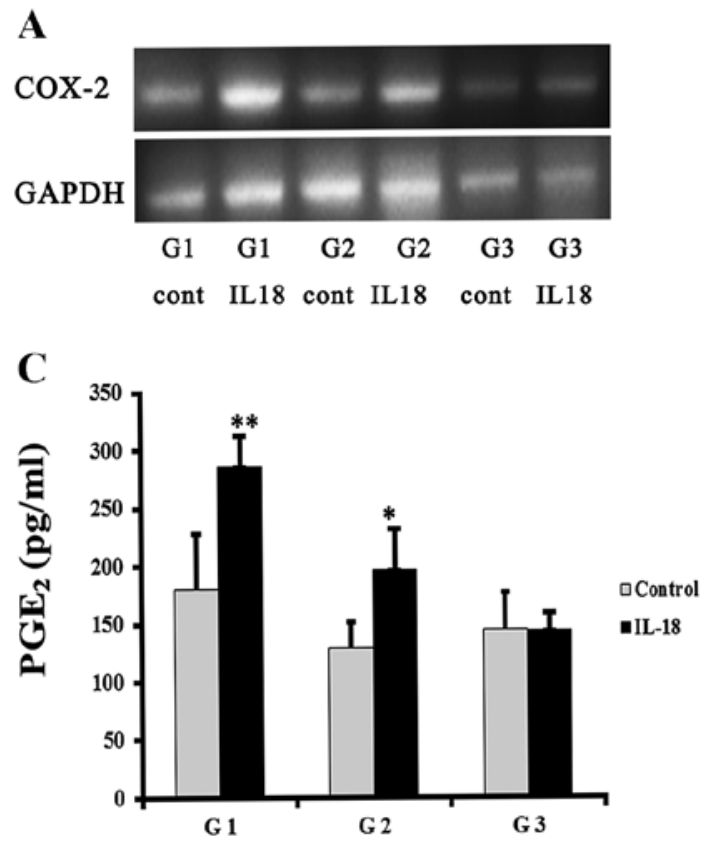
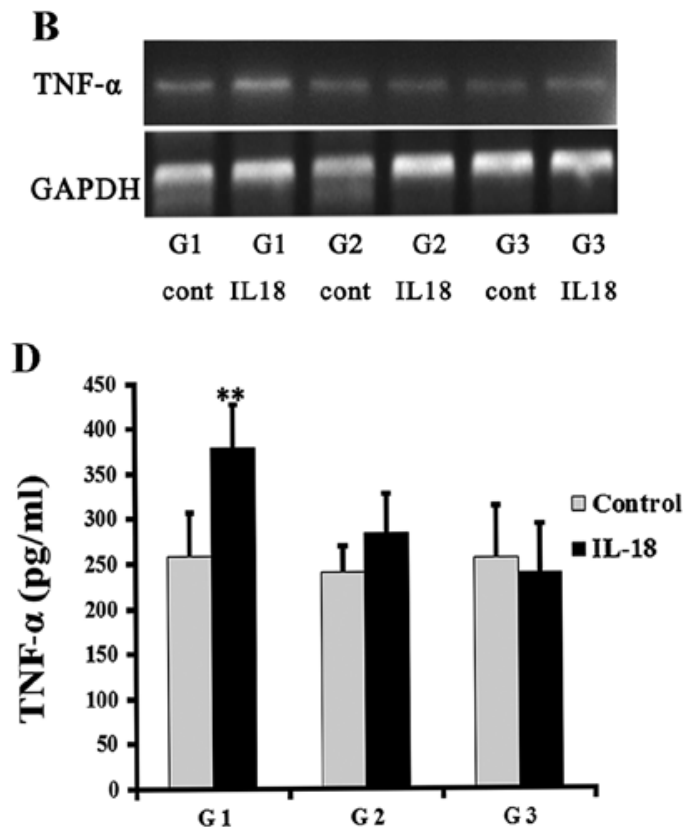

Figure 2. Expression of TNF- $\alpha$ and PGE 2 in synoviocytes is shown. (A) COX-2 and (B) TNF- $\alpha$ mRNA expression in synoviocytes was determined by RT-PCR GAPDH was used as an internal control. The levels of (C) $\mathrm{PGE}_{2}$ and (D) TNF- $\alpha$ in the supernatant were measured using ELISA. "P<0.05, compared to the control group; ${ }^{* *} \mathrm{P}<0.01$, compared to the control group. Cont, control group; IL-18, IL-18-treated group; G1, the first generation synoviocytes.

different IL-18 concentrations on synoviocytes were analyzed using one-way analysis of variance (ANOVA). When statistically significant difference was obtained, multiple comparisons were carried out, using the LSD test or Dunnetts' T3 test (unequal variances).

\section{Results}

Characterization and morphology of synoviocytes and chondrocytes. There were 2 morphological forms of primary synoviocytes (G1-synoviocytes): spindle-shaped fibroblast-like 


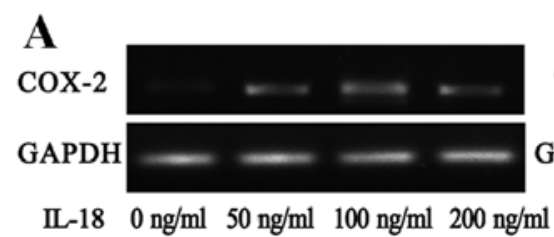

B

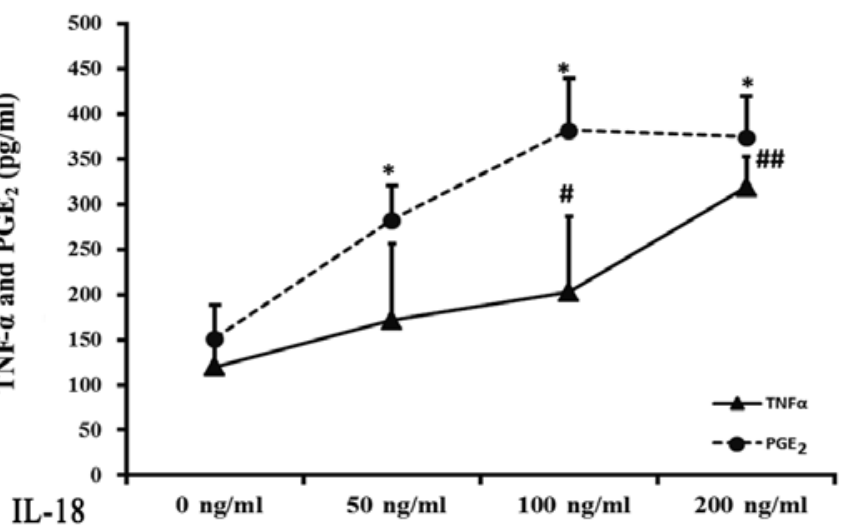

Figure 3. Effect of IL-18 on chondrocytes is shown. Chondrocytes were cultured in media containing different concentrations of IL-18 (0, 50 , 100 and 200 ng/ ml). (A) COX-2 and TNF- $\alpha$ expression was assessed using RT-PCR. GAPDH was used as an internal control. (B) The level of PGE ${ }_{2}$ in the supernatant was determined using ELISA. (C) The levels of COX-2 mRNA and $\mathrm{PGE}_{2}$, after being treated with IL-1Ra, were measured. * $<<0.01$, compared to the 0 ng/ml group; ${ }^{\#} \mathrm{P}<0.05$, compared to the $0 \mathrm{ng} / \mathrm{ml}$ group; ${ }^{\# \#} \mathrm{P}<0.01$, compared to the $0 \mathrm{ng} / \mathrm{ml}$ group. ${ }^{\psi} \mathrm{P}<0.01$, compared to the control group.

\section{A synoviocyte}
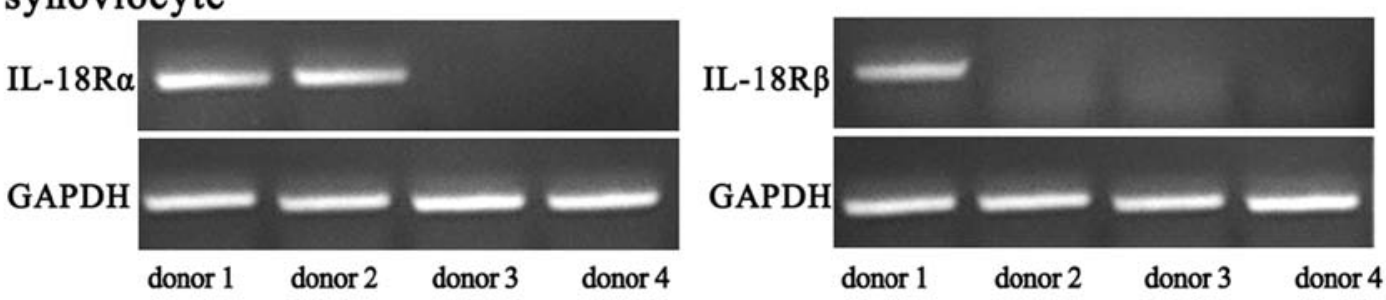

\section{B chondrocyte}
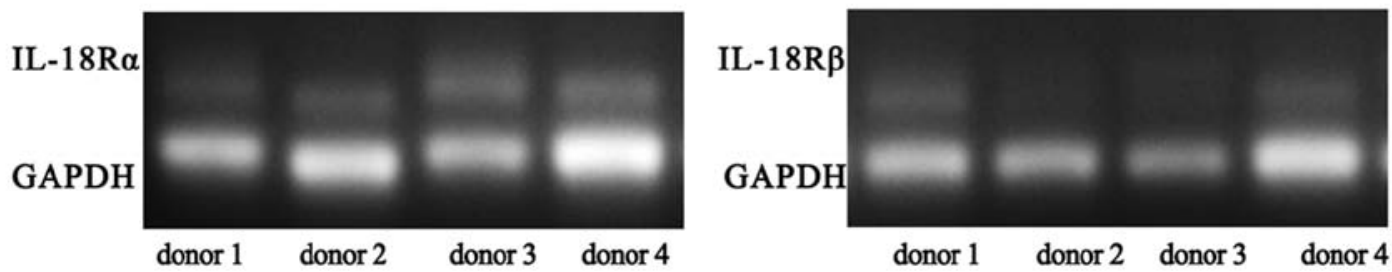

Figure 4. Expression of IL-18R in chondrocytes and synoviocytes is shown. The expression of IL-18R $\alpha$ and IL-18 $\beta$ mRNA in (A) synoviocytes and (B) chondrocytes from 4 donors was assessed by RT-PCR. GAPDH was used as the internal control.

synoviocytes and polygonal macrophage-like synoviocytes (Fig. 1Aa). The number of polygonal macrophage-like synoviocytes decreased in the secondary generation of synoviocytes (G2-synoviocytes) (Fig. 1Ab). The majority of cells in the third generation (G3-synoviocytes) were spindle-shaped, i.e., they were fibroblast-like synoviocytes (Fig. 1Ac). The numbers of the macrophage-like cells decreased with increasing passage numbers. Type I collagen expression in synoviocytes was detected by immunohistochemistry (Fig. 1B). The cytosol of the synoviocytes was stained brown, indicating a high level of type I collagen expression. Type I collagen expression in cells with the two forms was similar. Chondrocytes were stained with an antibody against type II collagen, while reticular type II collagen was visible in the intracellular space (Fig. 1Ca).

IL-18-induce inflammatory response in synoviocytes. G1- and G2-synoviocytes demonstrated an elevated COX-2 expression subsequent to IL-18 induction, while G3-synoviovytes showed no significant change (Fig. 2A). All the synoviocytes demonstrated in vitro $\mathrm{PGE}_{2}$ production. G1- and G2-synoviocytes in the IL-18-treated groups had markedly higher levels of $\mathrm{PGE}_{2}$ expression, compared to the control group (286.21 \pm 26.24 vs. $180.31 \pm 47.69 \mathrm{pg} / \mathrm{ml}, 196.60 \pm 34.79$ vs. $128.72 \pm 22.37 \mathrm{pg} / \mathrm{ml}$; $\mathrm{P}=0.005$ and $\mathrm{P}=0.011$, respectively) (Fig. 2C). Similarly, IL-18 induced mRNA expression in G1-synoviocytes, although not 
in G2-synoviocytes (Fig. 2B). The results were consistent with the protein assay results. There was a statistically significant difference in the TNF- $\alpha$ concentration in the G1-synoviocyte supernatant in the IL-18-treated and the control group (379.20 \pm 47.60 vs. $257.90 \pm 48.76$ pg/ml; $\mathrm{P}=0.007$ ) (Fig. 2D). However, G3-synoviocytes were less sensitive to IL-18 induction, whereas the TNF- $\alpha$ and $\mathrm{PGE}_{2}$ levels were not increased $(\mathrm{P}>0.05)$.

Response of the chondrocytes to IL-18 stimulation. An increase was observed in COX-2 and TNF- $\alpha$ mRNA expression with increasing concentrations of IL-18 (Fig. 3A). PGE 2 levels in the 50,100 and $200 \mathrm{ng} / \mathrm{ml}$ IL-18 groups were $282.83 \pm 52.16$, $381.85 \pm 84.15$ and $374.51 \pm 34.14 \mathrm{pg} / \mathrm{ml}$, respectively, which were significantly higher compared to the control group $(151.72 \pm 23.76 \mathrm{pg} / \mathrm{ml} ; \mathrm{P}=0.003, \mathrm{P}<0.001$ and $\mathrm{P}<0.001$, respectively). In addition, the 100 and $200 \mathrm{ng} / \mathrm{ml}$ IL-18 groups showed significantly higher TNF- $\alpha$ levels compared to the control group $(202.48 \pm 57.46$ and $318.63 \pm 45.23 \mathrm{pg} / \mathrm{ml} ; \mathrm{P}=0.002$ and $\mathrm{P}<0.001$, respectively) (Fig. 3B). The induction of $\mathrm{PGE}_{2}$ and TNF- $\alpha$ by IL-18 was dose-dependent.

To elucidate the correlation between IL-18 and IL-1 $\beta$ induced inflammatory responses in chondrocytes, chondrocytes in the IL-18 group were treated with $100 \mathrm{ng} / \mathrm{ml}$ IL-18, while those in the IL-1Ra group were treated with $100 \mathrm{ng} / \mathrm{ml} \mathrm{IL-18}$ and IL-1Ra. After 24-h incubation, the IL-18 group demonstrated a significantly higher COX-2 mRNA expression, compared to the other 2 groups (Fig. 3C). The IL-18 group also had a markedly higher level of $\mathrm{PGE}_{2}$, compared to the control group $(\mathrm{P}=0.003)$. The $\mathrm{PGE}_{2}$ level decreased following addition of the inhibitor, although this level was still higher when compared to the control group $(\mathrm{P}=0.002)$.

Expression of $I L-18 R$. The primary synoviocytes of 8 patients were obtained and analyzed. The synoviocytes of two of the 8 donors had detectable IL-18R $\alpha$ expression, and those of one donor had IL-18R $\beta$ expression (Fig. 4A). After passage, no receptor expression was detected. Chondrocytes from 4 donors expressed IL-18R $\alpha$, whereas those from 2 donors expressed IL-18R $\beta$ (Fig. 4B).

\section{Discussion}

The present study investigated the impact of IL-18 on synoviocytes and chondrocytes. The results showed that high levels of IL-18 induced the expression of inflammatory factors, such as TNF- $\alpha, \mathrm{PGE}_{2}$ and COX 2 in primary synoviocytes. With the increase of passage numbers, fibroblast-like cells became more dominant, IL-18R expression decreased, while the synoviocytes became less responsive to IL-18 stimulation. IL-18 had the potential to induce the expression of PGE 2 , TNF- $\alpha$ and COX-2 in human OA chondrocytes, which express IL-18R $\alpha$ and IL-18R $\beta$.

IL-18 induced inflammatory responses in OA synoviocytes. The knee synovial membrane is composed of two types of cells: the macrophage-like synoviocytes known as A cells, and the fibroblast-like synoviocytes known as B cells. Goto et al (21) have differentiated and purified these two types of cells, using cell cloning (20). Type A cells proliferate slowly, are less active and lose activity after 10 days of culture (22).
Primary synoviocytes from OA patients contained two cell types expressing IL-18. They produced high TNF- $\alpha, \mathrm{PGE}_{2}$ and COX-2 levels when induced by IL-18. Such a pro-inflammatory response is also noted in RA patient-derived synoviocytes. In a mouse model of collagen-induced arthritis (CIA), mature IL-18 induced synovial proliferation, synovial inflammation and cartilage damage (23). It has even been attempted to neutralize intrinsic IL-18 in RA patients with a view to treat the disease (24). Synoviocytes from OA patients express higher levels of IL-18 than those from healthy individuals. The elevated levels of typical inflammatory factors, such as $\mathrm{PGE}_{2}$ and TNF in OA in the joint fluid is closely associated with the clinical presentations of OA (25).

However, not all the synoviocytes are equally sensitive to IL-18. Primary cells secrete more inflammatory factors upon IL-18 stimulation. As passage numbers increased, the production of $\mathrm{PGE}_{2}$ and TNF- $\alpha$ was less affected by IL-18 treatment. In the present study, only IL-18R $\alpha$ was detected in primary OA synoviocytes, while IL-18R $\beta$ was virtually absent. This finding suggested that IL-18 targets A cells, instead of B cells. Since the number of A cells decreased or even disappeared with increasing culture time, IL-18R expression disappeared along with the pro-inflammatory effects of IL-18 on synoviocytes. This is similar to RA synoviocytes: IL-18 induces inflammation and joint destruction through the stimulation of T-cells and macrophages, instead of fibroblast-like synoviocytes, which lack IL-18R.

Excessive IL-18 triggers inflammatory responses in chondrocytes. In this study, IL-18 was found to be able to induce TNF- $\alpha$ and $\mathrm{PGE}_{2}$ expressions and to trigger excessive COX-2 production in chondrocytes. COX-2 degrades arachidonic acid to generate $\mathrm{PGE}_{2}$. An elevated level of $\mathrm{PGE}_{2}$ has the potential to generate the metabolic imbalance and degradation of cartilage (26). TNF- $\alpha$ is a contributing factor of inflammation in OA, and its level in the joint fluid is closely correlated with the progression of OA (27-29). In addition, in this study, all the OA chondrocytes expressed IL-18R $\alpha$, while certain cells expressed IL-18R $\beta$. IL-18 stimulates cells through the two receptors, triggering signal transduction via the $\mathrm{NF}-\kappa \mathrm{B}$ pathway thus inducing cellular inflammatory responses (30).

IL-18 and IL-1 $\beta$ affect chondrocytes in an interactive yet independent way. IL-1 $\beta$ promotes the secretion of inflammatory factors and MMPs in chondrocytes, leading to the degradation of cartilage matrix. IL-1 $\beta$ is considered to be a typical pro-inflammatory factor in OA pathogenesis $(31,32)$. IL-18 has similar functions to IL-1 $\beta$, while both promote the production of inflammatory factors in chondrocytes. Our results have demonstrated that IL-18 induced inflammatory responses in chondrocytes despite the blockage of the IL-1 $\beta$ function by IL-1Ra, although the $\mathrm{PGE}_{2}$ and TNF- $\alpha$ levels were lowered, indicating that the effect of IL-18 is only partially dependent on IL- $1 \beta$, possibly due to their distinct signaling transduction pathways. IL-18 induces COX-2 through the MAPK-p38-AP1 and NF- $\kappa$ B pathways $(33,34)$, whereas IL-1 $\beta$ induces MMP through the p38 APK/c-Fos/ AP-1 and JAK2/STAT1/2 pathways. The utilization of different signaling pathways by IL-18 and IL-1 $\beta$ led to their disparate effects on chondrocytes.

In conclusion, synoviocytes and chondrocytes from OA patients express IL-18R. IL-18 were able to induce 
inflammatory responses in the two types of cells. This pro-inflammatory effect was partially independent on IL-1 in chondrocytes.

\section{Acknowledgements}

This study was supported by research grants from the Guangdong Natural Science Foundation of China (S2011010003871) and the Research Fund for the Doctoral Program of Higher Education (20114433110016).

\section{References}

1. Haynes MK, Hume EL and Smith JB: Phenotypic characterization of inflammatory cells from osteoarthritic synovium and synovial fluids. Clin Immunol 105: 315-325, 2002.

2. Smith MD, Triantafillou S, Parker A, Youssef PP and Coleman M: Synovial membrane inflammation and cytokine production in patients with early osteoarthritis. J Rheumatol 24: 365-371, 1997.

3. Dinarello CA: The IL-1 family and inflammatory diseases. Clin Exp Rheumatol 20: S1-S13, 2002.

4. Bjornsson GL, Thorsteinsson L, Gudmundsson KO, Jonsson H Jr, Gudmundsson S and Gudbjornsson B: Inflammatory cytokines in relation to adrenal response following total hip replacement. Scand J Immunol 65: 99-105, 2007.

5. Dai SM, Shan ZZ, Xu H and Nishioka K: Cellular targets of interleukin-18 in rheumatoid arthritis. Ann Rheum Dis 66: 1411-1418 2007.

6. Mohtai M, Gupta MK, Donlon B, et al: Expression of interleukin-6 in osteoarthritic chondrocytes and effects of fluidinduced shear on this expression in normal human chondrocytes in vitro. J Orthop Res 14: 67-73, 1996.

7. Okamura H, Tsutsi $\mathrm{H}$, Komatsu $\mathrm{T}$, et al: Cloning of a new cytokine that induces IFN-gamma production by T cells. Nature 378: 88-91, 1995.

8. Ghayur T, Banerjee S, Hugunin M, et al: Caspase-1 processes IFN-gamma-inducing factor and regulates LPS-induced IFN-gamma production. Nature 386: 619-623, 1997.

9. Matsui K, Tsutsui H and Nakanishi K: Pathophysiological roles for IL-18 in inflammatory arthritis. Expert Opin Ther Targets 7: 701-724, 2003

10. Pawlik A, Kurzawski M, Drozdzik M, Dziedziejko V Safranow K and Herczynska M: Interleukin-18 gene (IL-18) promoter polymorphisms in patients with rheumatoid arthritis Scand J Rheumatol 38: 159-165, 2009.

11. Shao XT, Feng L, Gu LJ, et al: Expression of interleukin-18, IL-18BP, and IL-18R in serum, synovial fluid, and synovial tissue in patients with rheumatoid arthritis. Clin Exp Med 9: 215-221, 2009.

12. Moller B, Kukoc-Zivojnov N, Kessler U, et al: Expression of interleukin-18 and its monokine-directed function in rheumatoid arthritis. Rheumatology (Oxford) 40: 302-309, 2001.

13. Lotz M, Blanco FJ, von Kempis J, et al: Cytokine regulation of chondrocyte functions. J Rheumatol Suppl 43: 104-108, 1995.

14. Olee T, Hashimoto S, Quach J and Lotz M: IL-18 is produced by articular chondrocytes and induces proinflammatory and catabolic responses. J Immunol 162: 1096-1100, 1999.

15. Joosten LA, Smeets RL, Koenders MI, et al: Interleukin-18 promotes joint inflammation and induces interleukin-1-driven cartilage destruction. Am J Pathol 165: 959-967, 2004.

16. Zimmermann T, Kunisch E, Pfeiffer R, et al: Isolation and characterization of rheumatoid arthritis synovial fibroblasts from primary culture - primary culture cells markedly differ from fourth-passage cells. Arthritis Res 3: 72-76, 2001.
17. Franke S, Sommer M, Ruster C, et al: Advanced glycation end products induce cell cycle arrest and proinflammatory changes in osteoarthritic fibroblast-like synovial cells. Arthritis Res Ther 11: R136, 2009

18. Livak KJ and Schmittgen TD: Analysis of relative gene expression data using real-time quantitative PCR and the 2(-Delta Delta C(T)) method. Methods 25: 402-408, 2001.

19. Moller B, Kessler U, Rehart S, et al: Expression of interleukin-18 receptor in fibroblast-like synoviocytes. Arthritis Res 4: 139-144, 2002 .

20. Ueng WN, Chuang $\mathrm{CC}$ and Shih $\mathrm{CH}$ : Double-rib composite free transfer to reconstruct a single-spared lower extremity defect. J Trauma 38: 210-212, 1995.

21. Goto M, Sasano M, Yamanaka H, et al: Spontaneous production of an interleukin 1-like factor by cloned rheumatoid synovial cells in long-term culture. J Clin Invest 80: 786-796, 1987.

22. Ueng SW, Chuang DC, Cheng SL and Shih CH: Management of large infected tibial defects with radical debridement and staged double-rib composite free transfer. J Trauma 40: 345-350, 1996.

23. Gracie JA, Forsey RJ, Chan WL, et al: A proinflammatory role for IL-18 in rheumatoid arthritis. J Clin Invest 104: 1393-1401, 1999.

24. Plater-Zyberk C, Joosten LA, Helsen MM, et al: Therapeutic effect of neutralizing endogenous IL-18 activity in the collageninduced model of arthritis. J Clin Invest 108: 1825-1832, 2001.

25. Goldring MB, Otero M, Plumb DA, et al: Roles of inflammatory and anabolic cytokines in cartilage metabolism: signals and multiple effectors converge upon MMP-13 regulation in osteoarthritis. Eur Cell Mater 21: 202-220, 2011.

26. Li X, Ellman M, Muddasani P, et al: Prostaglandin E2 and its cognate EP receptors control human adult articular cartilage homeostasis and are linked to the pathophysiology of osteoarthritis. Arthritis Rheum 60: 513-523, 2009.

27. Chan BY, Fuller ES, Russell AK, et al: Increased chondrocyte sclerostin may protect against cartilage degradation in osteoarthritis. Osteoarthritis Cartilage 19: 874-885, 2011.

28. Maganev VA, Davletshin RA, Davletshina GK and Iapparov GS: Dynamics of tumour necrosis factor-alpha and clinical signs of osteoarthrosis during the treatment with alflutop in combination with peloid applications under conditions of health resort. Vopr Kurortol Fizioter Lech Fiz Kult, pp18-20, 2011 (In Russian).

29. Orita S, Koshi T, Mitsuka T, et al: Associations between proinflammatory cytokines in the synovial fluid and radiographic grading and pain-related scores in 47 consecutive patients with osteoarthritis of the knee. BMC Musculoskeletal Disord 12: 144, 2011.

30. Kawashima M and Miossec P: Heterogeneity of response of rheumatoid synovium cell subsets to interleukin-18 in relation to differential interleukin-18 receptor expression. Arthritis Rheum 48: 631-637, 2003.

31. Lim H and Kim HP: Matrix metalloproteinase-13 expression in IL-1 $\beta$-treated chondrocytes by activation of the p38 MAPK/c-Fos/AP-1 and JAK/STAT pathways. Arch Pharm Res 34: 109-117, 2011.

32. Singh R, Ahmed S, Malemud CJ, Goldberg VM and Haqqi TM: Epigallocatechin-3-gallate selectively inhibits interleukin-1betainduced activation of mitogen activated protein kinase subgroup c-Jun N-terminal kinase in human osteoarthritis chondrocytes. J Orthop Res 21: 102-109, 2003.

33. Chandrasekar B, Mummidi S, Mahimainathan L, et al: Interleukin-18-induced human coronary artery smooth muscle cell migration is dependent on NF-kappaB- and AP-1-mediated matrix metalloproteinase-9 expression and is inhibited by atorvastatin. J Biol Chem 281: 15099-15109, 2006

34. Lee JK, Kim SH, Lewis EC, Azam T, Reznikov LL and Dinarello CA: Differences in signaling pathways by IL-1beta and IL-18. Proc Natl Acad Sci USA 101: 8815-8820, 2004. 